\title{
Utilization of Trimethylolpropane Based Hyperbranched Poly (Amine-Ester) as New Polymeric Admixture
}

\author{
Amal Amin Ibrahim ${ }^{1}$, Ahmed El-Sayed Abdel-Magied², \\ Mohamed Sayed Selim ${ }^{1}$, Magdy Mohamed Hussein Ayoub ${ }^{1}$ \\ ${ }^{1}$ Polymers and Pigments Department, National Research Center, Dokki, Giza, Egypt \\ ${ }^{2}$ Organic Chemistry Department, Menoufiya University, Shebin El-Kom, Egypt \\ Email: aamin_07@yahoo.com
}

Received February 10, 2012; revised March 12, 2012; accepted March 27, 2012

\begin{abstract}
Hyperbranched poly (amine-ester) (HBPAE) was synthesized via pseudo-one-step process between trimethylolpropane as a core molecule and $\mathrm{N}, \mathrm{N}$-diethylol-3-amine methylpropionate as the $\mathrm{AB}_{2}$ branched monomer. The prepared polymer was analyzed by IR, GPC, ${ }^{1} \mathrm{H}-\mathrm{NMR}$ and thermal analysis (TGA and DSC). The performance of the polymer in cement was tested by measuring the effect of 1,3 and $5 \mathrm{wt} \%$ of HBPAE solutions on the properties of Ordinary Portland Cement. Water of consistency, setting times, bulk density, apparent porosity, compressive strength and combined water content of the polymer/cement pastes were studied. The results showed that water of consistency and apparent porosity decreased while setting times, compressive strength, combined water and bulk density increased with the polymer addition.
\end{abstract}

Keywords: Hyperbranched Polymers; Poly (Amine-Ester); Ordinary Portland Cement; Compressive Strength

\section{Introduction}

Dendrimers [1] and hyperbranched polymers [2-4], are attracted considerable attention from both industry and academia because of their remarkable vital properties such as reduction of melt and solution viscosity, high solubility, high functionalities due to large number of reactive end-groups within a molecule, approximately spherical molecular shape and the absence of chain entanglement. [5-7] However, dendrimers are prepared via step-wise reactions which require several purification processes although they have well controlled structures. $[8,9]$ On contrary, hyperbranched polymers are easily prepared counterparts in one-step reactions, and typically have the branches randomly distributed though the polymers which make them attractive alternatives to dendrimers to some extent for many applications. $[10,11]$ Several hyperbranched polymers in different chemical architectures are prepared now by well-known mechanisms such as polyesters, polyamides, polyacrylates, polysiloxysilanes, and others. [12,13] Hyperbranched polymers are potentially used as additives especially when high mechanical strength is required for a certain application [14], functional cross-linkers, rheology modifiers, drug and gene delivery, electroactive and photochemical molecular devices, conductive materials as well as components in adhesives, advanced and structured hydrogels for biomedical applications and building blocks of functional materials. Also, polyesteramides hyperbranched polymers were used successfully by our research group in the building industry as cement admixtures as new application for them [15].

Thereby, hyperbranched polymers acted as water reducing agents which interacted with the surface of cement particles, involving dispersion and decreasing their natural tendency to coagulate in aqueous systems. As a result, highly flowable mortars and concretes were obtained which showed increased workability at constant lower water/cement ratios [16].

Generally, there are four different polymeric chemical admixtures such as modified ligno sulfonated polymers (LS), naphthalene formaldehyde sulfonated polymers (N), melamine formaldehyde sulfonated polymers (S), and polycarboxylate derivates (CE). [17,18] Water-soluble polymers such as sulfonated phenolic resin (SPF) and sulfonated acetone formaldehyde (SAF) have also been used successfully in this area. [19] Polymer/cement paste is normally made by mixing either a monomer or polymer in dispersion, powdery, or liquid form with cement and subsequently curing it.

In this work, water soluble hyperbranched poly amineester (HBPAE) was prepared by the reaction of 1, 1, 1trimethylolpropane and N, N-diethylol-3-amine methylpropionate as indicated in Scheme 1. Then, the resulting 
hyperbranched polymer was involved as a new polymeric admixture in the cement pastes.

\section{Experimental}

\subsection{Materials}

1, 1, 1-Trimethylolpropane, diethanolamine, methyl-acrylate and p-toluene sulphonic acid were provided by SigmaAldrich. The OPC with blain surface area of $3300 \mathrm{~cm}^{2} / \mathrm{g}$ was delivered from El-masria Cement Company, Egypt. The chemical composition of OPC is shown in Table $\mathbf{1 .}$

\subsection{Instrumentation}

The prepared polymer was characterized using different techniques such as Infrared spectra (IR), gel permeation chromatography (GPC), nuclear magnetic resonance $\left({ }^{1} \mathrm{H}\right.$ NMR), thermal gravimetric analyses (TGA) and differential scanning calorimetry (DSC). IR spectra were recorded by JASCO in the range of $4000-400 \mathrm{~cm}^{-1}$. The number-average molecular weight $\left(\bar{M}_{n}\right)$ and the polydispersity index $\left(\bar{M}_{w} / \bar{M}_{n}\right)$ of the polymer were measured by GPC via GPC-1100 Agilent technologies by using polystyrene (PS) as standard and $\mathrm{N}, \mathrm{N}$-dimethylformamide (DMF) as eluent with flow rate $1 \mathrm{ml} / \mathrm{min} .{ }^{1} \mathrm{H}-\mathrm{NMR}$ spectrum was obtained by Varian Mercury spectrometer at $300 \mathrm{MHz}$, using tetramethylsilane (TMS) as internal standard and DMSO- $\mathrm{d}_{6}$ as the main solvent. TGA was carried out by using TGA-50 shimadzu instrument till $400^{\circ} \mathrm{C}$ with heating rate $10 \mathrm{~K} \cdot \mathrm{min}^{-1}$. DSC was measured via differential scanning calorimeter DSC-60 shimadzu from $-20^{\circ} \mathrm{C}$ to $80^{\circ} \mathrm{C}$ with scanning rate of $20 \mathrm{~K} \mathrm{~min}^{-1}$ under nitrogen atmosphere. Vicat apparatus was used to measure the standard water of consistency (or w/c ratio) as well as the setting times (initial and final) of the cement pastes. [15,16,20,21] Bulk density (B.D) and apparent porosity (A.P.) of the hardened cement pastes were calculated from Equations (1) and (2), respectively: [20].<smiles>C=CC(=O)OCCNC(C)CCO</smiles>

(I)<smiles>CC(O)C(CO)CO</smiles>

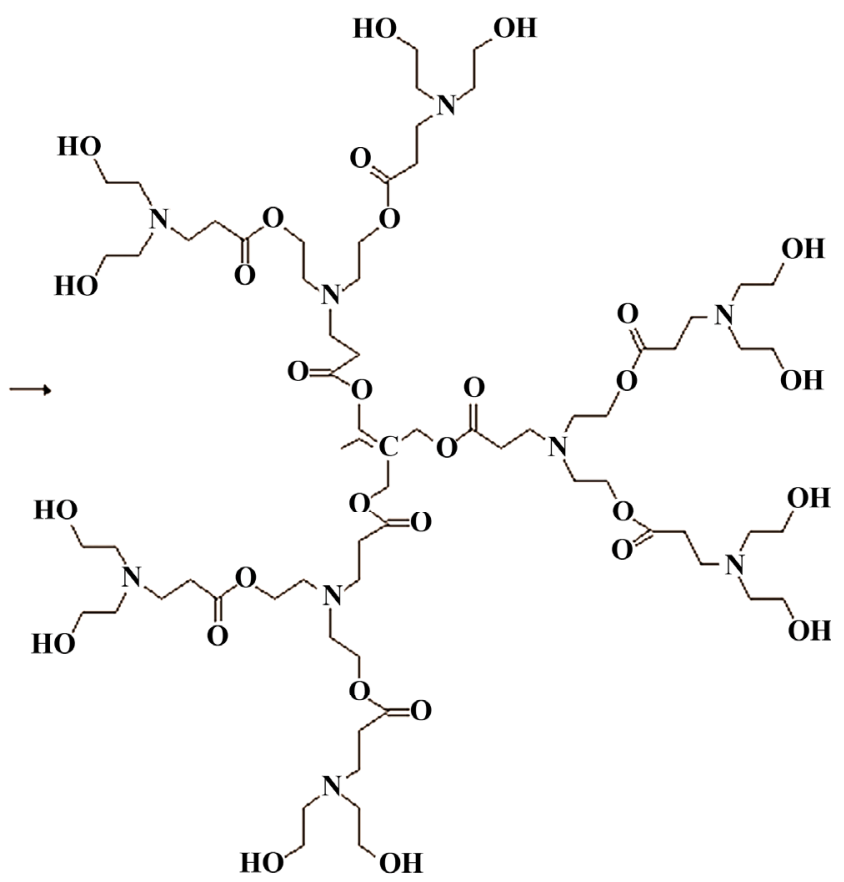

Scheme 1. Synthesis of hyperbranched poly (amine-ester).

Table 1. Chemical composition of the OPC cement, wt\%.

\begin{tabular}{cccccccccc}
\hline Materials Oxides & L.O.I & $\mathrm{SiO}_{2}$ & $\mathrm{Al}_{2} \mathrm{O}_{3}$ & $\mathrm{Fe}_{2} \mathrm{O}_{3}$ & $\mathrm{CaO}$ & $\mathrm{MgO}$ & $\mathrm{Na}_{2} \mathrm{O}$ & $\mathrm{K}_{2} \mathrm{O}$ & $\mathrm{SO}_{3}$ \\
\hline OPC & 2.64 & 20.12 & 5.25 & 3.38 & 63.13 & 1.53 & 0.55 & 0.3 & 2.54 \\
\hline
\end{tabular}

L.O.I $=$ Loss of ignition. 


$$
\begin{aligned}
& \text { B.D. }\left(\mathrm{g} / \mathrm{cm}^{3}\right)=W_{1} /\left(W_{1}-W_{2}\right) \times 1 \\
& \text { A.P. }(\%)=\left(W_{1}-W_{3}\right) /\left(W_{1}-W_{2}\right) \times 100
\end{aligned}
$$

where $W_{1}, W_{2}, W_{3}=$ saturated, suspended and dry weights. Compressive strength measurements [18] of the cement pastes were carried out by using hydraulic testing machine of the Type LPM 600 M1 SEIDNER (Germany). The chemically-combined water content at each time interval was determined on the basis of ignition loss $[15,16]$ where the chemically combined water is defined as that portion present in interlayer spaces, or more firmly nonevaporable water. [22]

\subsection{Synthesis of Hyperbranched Poly (Amine-Ester)}

The prepared hyperbranched poly (amine-ester) as shown in Scheme 1 was prepared as mentioned elsewhere in the literature [23] where it had trimethylolpropane as a core and N, N-diethylol-3-amine methylpropionate as the $\mathrm{AB}_{2}$ branched monomer. N, N-diethylol-3-amine methylpropionate (I) was prepared via Michael addition of methyl acrylate and diethanolamine in methanol through vaccum distillation. Faint yellow oily liquid (I) was obtained. Subsequently, $0.1 \mathrm{~mol}$ of 1, 1, 1-trimethylolpropane, 0.3 mol of (I) and $0.5 \mathrm{wt} \%$ of p-toluene sulphonic acid as catalyst were stirred at $120^{\circ} \mathrm{C}$. The unreacted residuals were removed by vaccum distillation.

\subsection{Preparation of Cement Mixes [15,16]}

Three polymer solutions with different concentrations, $1 \%, 3 \%$, and $5 \%$, were prepared. The upper limit of the added hyperbranched polymer to the solid mass of cement was $1.667 \%$ and to the used solution of mixing is $5 \%$. Each polymer solution was mixed separately with Ordinary Portland Cement, to study the effect of polymer addition on the properties of cement in the resulting polymer/cement pastes with respect to the blank-cement samples. Water of consistency and setting time measurements were carried out on both of blank and polymer/ cement samples by adding water or polymer solutions gradually to cement and tested with Vicat apparatus. $\mathrm{Cu}-$ bic samples of blank and polymer/cement admixtures were made and immersed in water basin for different time periods $(1,3,7,28$ days) then they were subjected to compressive strength measurements by using the hydraulic press machine. Chemically combined water can be calculated from the following equation.

$$
W_{n}=W_{1}-W_{2} \times 100
$$

$W_{1}=$ Weight before ignition, $W_{2}=$ ignited weight where the combined water $\left(W_{n}\right)$ is considered as the ignition loss.

\section{Results \& Discussion}

Hyperbranched polymer (HBPAE) was synthesized via pseudo-one-step process between tri-methylolpropane as a core molecule and $\mathrm{N}, \mathrm{N}$-diethylol-3-amine methylpropionate as the $\mathrm{AB}_{2}$ branched monomer (Scheme 1). [23] HBPAE was characterized by GPC, IR, ${ }^{1} \mathrm{H}-\mathrm{NMR}$, TGA and DSC. GPC recorded the number-average molecular weight $\left(\bar{M}_{n}\right)$ and the polydispersity index $\left(\bar{M}_{w} / \bar{M}_{n}\right)$ for HBPAE as $3695 \mathrm{~g} / \mathrm{mol}$ and 2.65 , respectively. IR spectrum of the prepared polymer revealed that, the two bands at $2879 \mathrm{~cm}^{-1}$ and $2941 \mathrm{~cm}^{-1}$ were due to $\mathrm{C}-\mathrm{H}$ stretching and the band at $1729 \mathrm{~cm}^{-1}$ represented the $\alpha$-unsaturated carbonyl of the ester group. The broad absorption band at $3398 \mathrm{~cm}^{-1}$ was assigned to hydroxyl groups which were H-bonded and those bands at 1064 $\mathrm{cm}^{-1}, 1112 \mathrm{~cm}^{-1}$ and $1265 \mathrm{~cm}^{-1}$ were attributed to $\mathrm{C}-\mathrm{O}$ and $\mathrm{C}-\mathrm{N}$ stretches. ${ }^{1} \mathrm{H}-\mathrm{NMR}$ spectrum of HBPAE showed as in (Figure 1) distinguished signals of chemical shifts at 1.39 ppm which were associated with the methyl protons and those from $2-2.28 \mathrm{ppm}, 2.5-3.2$ ppm were assigned to $\left(\mathrm{CH}_{3} \mathrm{CH}_{2}^{-}\right)$and $\left(\mathrm{CH}_{3} \mathrm{CH}_{2} \mathrm{CR}_{3}\right)$. Other signals at $3.3 \mathrm{ppm}, 3.4-3.6 \mathrm{ppm}$ and $3.6-3.8$ were ascribed to $\left(-\mathrm{N}\left(\mathrm{CH}_{2} \mathrm{CH}_{2} \mathrm{OH}\right)_{2}\right),\left(-\mathrm{N}\left(\mathrm{CH}_{2} \mathrm{CH}_{2} \mathrm{OH}\right)_{2}\right.$, and $\left(\mathrm{OCOCH}_{2} \mathrm{CH}_{2} \mathrm{NR}_{2}\right)$. Signals at $4.1-4.3 \mathrm{ppm}, 4.4$ ppm and $4.6 \mathrm{ppm}$ were assigned to $\left(\mathrm{R}^{\prime} \mathrm{R}_{2} \mathrm{CCH}_{2}-\mathrm{OCO}\right)$, $\left(-\mathrm{OCOCH}_{2} \mathrm{CH}_{2}\right)$ and the proton of hydroxyl group $\left(-\mathrm{CH}_{2} \mathrm{CH}_{2} \mathrm{OH}\right)$. TGA of HBPAE as shown in (Figure 2)

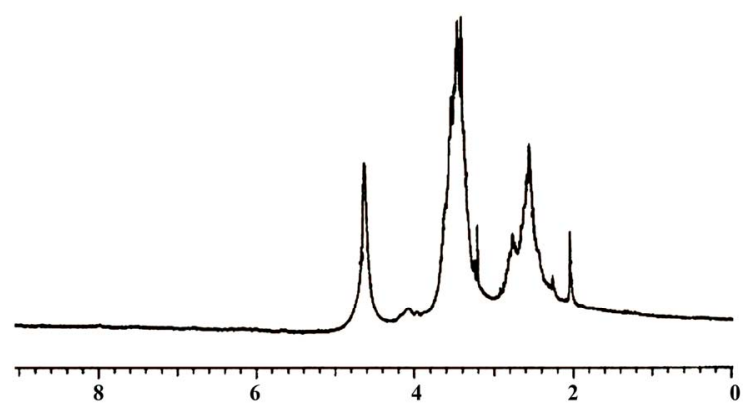

Figure $1 .{ }^{1}$ HNMR of HBPAE.

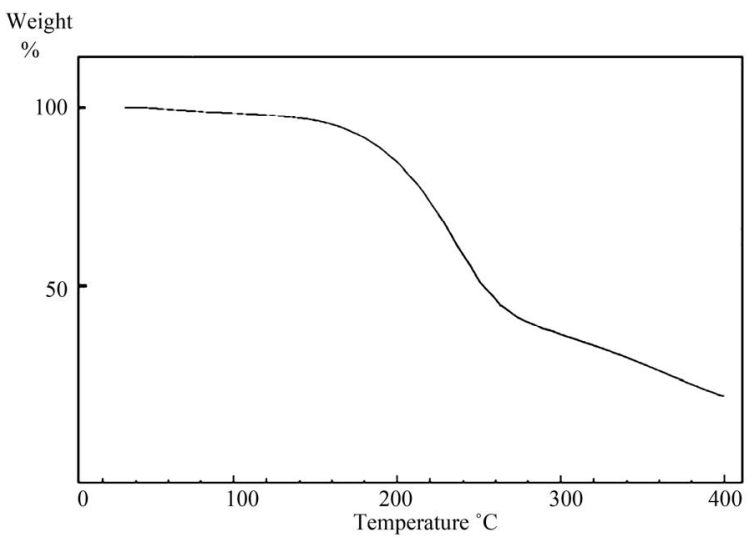

Figure 2. TGA of HBPAE. 
exhibited relative thermal stability till $193.6^{\circ} \mathrm{C}$ where the weight loss was just 5\%. The weight loss reached $10 \%$ at $254.5^{\circ} \mathrm{C}$, however, TG curve of the hyperbranched poly (amine-ester) descended when the temperature reached the range of $290^{\circ} \mathrm{C}-390^{\circ} \mathrm{C}$. That might be due to the decomposition of amine and ester bonds in the hyperbranched poly amine-ester. DSC measurements recorded $\mathrm{T}_{\mathrm{g}}$ value as $22.83^{\circ} \mathrm{C}$. The previous data confirmed the expected structure of the resulting polymer with hydroxyl, ester, and amine groups.

Hyperbranched HBPAE polymer was involved in cement as good application for the hyperbranched polymers in construction materials. On that way, different concentrations of polymer were added to the OPC to obtain versatile polymer/cement pastes. Several measures were performed for that purpose on the resulting polymer/cement pastes such as water of consistency, setting times, bulk density, apparent porosity, compressive strength and combined water content of the polymer/cement pastes.

The results of water of consistency as well as setting times (initial and final) of the OPC cement pastes premixed with variable concentrations of HBPAE are demonstrated in Table 2. Generally, the water of consistency gradually decreased with increasing the polymer content up to $5 \%$. Using polymer concentration of (5\%), the water of consistency decreased from $30 \%$ to $24.32 \%$ for OPC. The water of consistency was highly reduced by $4.33 \%-5.68 \%$ for OPC, when compared with that of the blank. So, it can be concluded that this polymer acted as water reducers. [23] Although the polymer lowered the water of consistency, it increased the setting times (initial and final). As shown in Table 2, the initial and final setting times increased from 120 to 155 minutes and 230 to 280 minutes with increasing HBPAE concentration. That meant HBPAE behaved as a retarder. The reduction in water of consistency and the elongation of setting times at the same time were attributed to the adsorption of the highly polar polymer molecules on the cement particles and hence, the subsequent formation of a polymer film. An electrostatic repulsion between the negatively charged cement particles formed, which reduced the interparticle attraction between the cement particles and then, prevented flocculation or agglomeration for them. That partial or full encapsulation of cement hydrates by the polymer molecules retarded the hydration process. So, the used polymer acted as a water reducing admixture and also as a setting-retarder.

Chemically-combined water contents of OPC cement pastes premixed with $1 \%, 3 \%$ and $5 \%$ of HBPAE are shown in Table 3 as a function of polymer concentration. The combined water contents of all cement pastes generally increased with curing time. That was mainly attributed to the gradual and continuous formation of the hydration products resulting from the hydration of the main phases of cement, particularly $\mathrm{C}_{3} \mathrm{~S}$ and $\beta-\mathrm{C}_{2} \mathrm{~S}$. The combined water contents increased with polymer concentration. The higher values of combined water contents by incorporation of small amounts of polymer with OPC were largely due to the dispersion effect of the polymer to the cement grains, which in turn prevented their aggregation and thus improved the hydration process.

Table 2. Water of consistency and setting times (initial and final) measurements of OPC premixed with $1 \%, 3 \%$ and $5 \%$ of HBPAE.

\begin{tabular}{cccc}
\hline & & \multicolumn{2}{c}{ Setting time (min) } \\
\cline { 3 - 5 } Polymer $(\mathrm{wt} \%)$ & Water of consistency $(\%)$ & Initial set & Final set \\
\hline 0 & 30.00 & 120 & 230 \\
1 & 28.00 & 130 & 250 \\
3 & 25.67 & 150 & 270 \\
5 & 24.33 & 155 & 280 \\
\hline
\end{tabular}

Table 3. Combined water content measurements of OPC pastes and those premixed with $1 \%$, $3 \%$ and $5 \%$ of $\mathrm{HBPAE}$ up to 28 days.

\begin{tabular}{|c|c|c|c|c|c|}
\hline \multirow{2}{*}{ Property } & \multirow{2}{*}{ Polymer concentration (wt $\%$ ) } & \multicolumn{4}{|c|}{ Curing time (days) } \\
\hline & & 1 & 3 & 7 & 28 \\
\hline \multirow{4}{*}{ Chemically combined water } & 0 & 25.14 & 25.91 & 26.54 & 27.67 \\
\hline & 1 & 26.48 & 26.93 & 27.83 & 28.37 \\
\hline & 3 & 25.98 & 26.93 & 27.98 & 29.75 \\
\hline & 5 & 27.24 & 27.89 & 28.85 & 30.47 \\
\hline
\end{tabular}


Table 4. Bulk density and apparent porosity of OPC cement pastes premixed with $1 \%$, $3 \%$ and $5 \%$ HBPAE up to 28 days.

\begin{tabular}{|c|c|c|c|c|c|}
\hline \multirow{2}{*}{ Property } & \multirow{2}{*}{ Polymer concentration ( $w t \%)$} & \multicolumn{4}{|c|}{ Curing time (days) } \\
\hline & & 1 & 3 & 7 & 28 \\
\hline \multirow{4}{*}{$\begin{array}{l}\text { Bulk density } \\
\mathrm{gm} / \mathrm{m}^{3}\end{array}$} & 0 & 1.5527 & 1.6032 & 1.6311 & 1.6833 \\
\hline & 1 & 1.6124 & 1.7456 & 1.7701 & 1.8227 \\
\hline & 3 & 1.6742 & 1.7938 & 1.8102 & 1.864 \\
\hline & 5 & 1.6562 & 1.8173 & 1.8387 & 1.8791 \\
\hline \multirow{4}{*}{$\begin{array}{c}\text { Apparent porosity } \\
\%\end{array}$} & 0 & 18.75 & 18.35 & 16.78 & 16.45 \\
\hline & 1 & 18.29 & 17.82 & 16.5 & 16.31 \\
\hline & 3 & 18.34 & 17.76 & 16.09 & 16.04 \\
\hline & 5 & 18.46 & 17.6 & 16.02 & 15.78 \\
\hline
\end{tabular}

Table 5. Compressive strength measurements of OPC pastes and those premixed with $1 \%$, $3 \%$ and $5 \%$ of HBPAE up to 28 days.

\begin{tabular}{|c|c|c|c|c|c|}
\hline \multirow{2}{*}{ Property } & \multirow{2}{*}{ Polymer concentration $(\mathrm{wt} \%)$} & \multicolumn{4}{|c|}{ Curing time (days) } \\
\hline & & 1 & 3 & 7 & 28 \\
\hline \multirow{4}{*}{ Compressive strength (MPa) } & 0 & 20.4 & 25.6 & 30.5 & 36 \\
\hline & 1 & 20.6 & 32.1 & 36.3 & 42.5 \\
\hline & 3 & 23.1 & 37.49 & 44.1 & 49.2 \\
\hline & 5 & 22.9 & 39.1 & 46.5 & 51.7 \\
\hline
\end{tabular}

The bulk density and apparent porosity of OPC cement pastes and those premixed with 1\%, 3\% and 5\% HBPAE are shown in Table 4. The bulk density of all cement mixes increased gradually with curing time while the apparent porosity decreased. That was attributed to the continual deposition of the formed hydration products in the pore structure of the hardened cement pastes. Thus, the apparent porosity decreased and hence the bulk density enhanced. Moreover, the bulk density was further improved with increasing the polymer concentration. The higher density values with HBPAE might be attributed to the improvement in the hydration process and subsequently the increase in the hydration products compared with that of the blank samples.

The compressive strength of OPC cement pastes premixed with $1 \%, 3 \%$ and 5\% HBPAE was measured as a function of curing time as illustrated in Table 5. The compressive strength of the hardened cement pastes generally increased with curing time. That was mainly attributed to the continual formation of the hydration products which deposited into the pores of the cement pastes. Thereby, the apparent porosity decreased gradually and the compactness increased. Hence, the bulk density increased by time of hydration. As a result, the compressive strength improved and enhanced. Higher compressive strength values were obtained for OPC cement by increasing the polymer concentration when compared with those of the blank samples at all curing periods, except at the first 24 hours of hydration. That behavior was due to some extent to both of the high activation effect of the hyperbranched poly (amine-ester) at later stages and also to the decrease of the apparent porosity which was resulted from further increase of the hydration products. [24] Furthermore, the dispersing effect of the hyperbranched polymers/cement pastes improved the workability of such pastes. Therefore, an enhancement of the compressive strength was obtained [25].

\section{Conclusion}

The hyperbranched poly (amine-ester) (HBPAE) reduced the water of consistency for OPC cement pastes comparing to the blank. Also, HBPAE activated the cement phases and improved the rate of hydration. Therefore, this class of hyperbranched polymers can be used as water-reducing agent or cement admixtures. Also, the combined water contents and compressive strength were improved and enhanced by using HBPAE at all curing ages of hydration particularly at later stages.

\section{REFERENCES}

[1] M. Fischer and F. Vögtle, "Dendrimers: From Design to Application," Angewandte Chemie International Edition, Vol. 38, No. 7, 1999, pp. 884-905. 
doi:10.1002/pola.10824

[2] J. M. J. Fréchet, M. Henmi, I. Gitsov, S. Aoshima, M. Leduc and R.B. Grubbs, "Self-Condensing Vinyl Polymerization: An Approach to Dendritic Materials," Science, Vol. 269, No. 5227, 1995, pp. 1080-1084.

[3] P. Bharathi and J. S. J. Moore, "Solid-Support Hyperbranched Polymerization: Evidence for Self-Limited Growth," Journal of the American Chemical Society, Vol. 119, No. 14, 1997, pp. 3391 3392. doi:10.1021/ja9632062

[4] H. Magnusson, E. Malmström and A. Hult, "Structure Buildup in Hyperbranched Polymers from 2,2-Bis(Hydroxymethyl) Propionic Acid," Macromolecules, Vol. 33, No. 8, 2000, pp. 3099-3104.

[5] C. Gao and D. Yan, "“ $\mathrm{A}_{2}+\mathrm{CB}_{n}$ ' Approach to Hyperbranched Polymers with Alternating Ureido and Urethano Units," Macromolecules, Vol. 36, No. 3, 2003, pp. 613620.

[6] M. Jikei and M. Kakimoto, "Hyperbranched Polymers: A Promising New Class of Materials," Progress in Polymer Science, Vol. 26, No. 8, 2001, pp. 1233-1285. doi:10.1016/S0079-6700(01)00018-1

[7] K. Fang, Z. Xu, X. Jiang, X. Zhang and S. Fu, "Preparation and Characterization of Hyperbranched Polyesteramides," Polymer Bulletin, Vol. 60, No. 4, 2008, pp. 533543.

[8] D. A. Tomalia and J. M. J. Fréchet, "Discovery of Dendrimers and Dendritic Polymers: A Brief Historical Perspective," Journal of Polymer Science Part A: Polymer Chemistry, Vol. 40, No. 16, 2002, pp. 2719-2728. doi:10.1002/pola.10301

[9] V. Martinez, S. Mecking, T. Tassaing, M. Besnard. S. Moisan. F. Cansell and C. Aymonier, "Dendritic CoreShell Macromolecules Soluble in Supercritical Carbon Dioxide," Macromolecules, Vol. 39, No. 12, 2006, pp. 3978-3979. doi:10.1021/ma0607315

[10] B. Liu, A. Kazlauciunas, J. T. Guthrie and S. Perrier, "One-Pot Hyperbranched Polymer Synthesis Mediated by Reversible Addition Fragmentation Chain Transfer (RAFT) Polymerization," Macromolecules, Vol. 38, No. 6, 2005, pp. 2131-2136. doi:10.1021/ma048035x

[11] D. Konkolewicz, O. Thorn-Seshold and A. Gray-Weale, "Models for Randomly Hyperbranched Polymers: Theory and Simulation," Journal of Chemical Physics, Vol. 129, No. 5, 2008, Article ID: 054901. doi:10.1063/1.2939242

[12] T. Sato, N. Sato, M. Seno and T. Hirano, "InitiatorFragment Incorporation Radical Polymerization of Divinylbenzene in the Presence of Glyoxylic Oxime Ether: Formation of Soluble Hyperbranched," Journal of Polymer Science Part A: Polymer Chemistry, Vol. 41, No. 19, 2003, pp. 3038-3047. doi:10.1002/pola.10824

[13] Y. H. Kim, "Hyperbranched Polymers 10 Years After," Journal of Polymer Science Part A: Polymer Chemistry, Vol. 36, No. 11, 1998, pp. 1685-1698.
doi:10.1002/(SICI)1099-0518(199808)36:11<1685::AIDPOLA1>3.3.CO;2-4

[14] H. Ihre, M. Johansson, E. Malmström, A. Hult and G. R. Newkome, "Advances in Dendritic Macromolecules," JAI Press, London, 1996.

[15] A. Amin, S. Morsi, H. H. M. Darweesh and M. M. H. Ayoub, "Effect of Phthalic Anhydride-Based HyperBranched Polyesteramide on Cement Characteristics," Journal of Applied Polymer Science, Vol. 120, No. 5, 2011, pp. 3054-3064. doi:10.1002/app.33484

[16] A. Amin, S. Morsi, H. H. M. Darweesh and M. M. H. Ayoub, "Modification of Cement with Succinic AnhyDride-Based Hyperbranched Polyesteramide," Journal of Applied Polymer Science, Vol. 124, No. 2, 2011, pp. 309320. doi:10.1002/app.35156

[17] F. Kreppelt, M. Weibel, D. Zampini and M. Romer, "Influence of Solution Chemistry on the Hydration of Polished Clinker Surfaces-A Study of Different Types of Polycarboxylic Acid-Based Admixtures," Cement Concrete Research, Vol. 32, No. 2, 2002, pp. 187-198. doi:10.1016/S0008-8846(01)00654-8

[18] A. K. Yamad, T. Takahashi, S. Hanehara and A. M. Matsuhis, "Effects of the Chemical Structure on the Properties of Polycarboxylate-Type Superplasticizer," Cement Concrete Research, Vol. 30, No. 2, 2000, pp. 197-207.

[19] M. Pei, Y. Yang, X. Zhang, J. Zhang and J. Dong, "Synthesis and the Effect of Water-Soluble Sulphonated Acetone-Formaldhyde Resin on the Properties of Concrete," Cement Concrete Research, Vol. 34, No. 8, 2004, pp. 1417 1420. doi:10.1016/j.cemconres.2004.01.012

[20] STM C 187-98, "Standard Test Method for Normal consistency of Hydraulic Cement," 1998.

[21] STM C 170-90, "Standard Test Method for Compressive Strength of Dimension Stone," 1993.

[22] P. C. Hewlett., "Lea's Chemistry of Cement and Concrete;" 4th Edition, John Wiley \& Sons Inc., New York, 1998.

[23] J. Zhang, Y. Zheng, P. Yu, S. Mo and R. Wang, "Synthesis of functionalized cArbon Nanotubes by Hyperbranched Poly (Amine-Ester) with Liquid Like Behavior at Room Temperature," Polymer, Vol. 50, No. 13, 2009, pp. 2953-2957.

[24] T. A. Misev, R. A. T. M. Van Benthem and T. J. G. Zwartkruis, "Calculating Techniques for Formulating and Modifying Hyperbranched Polycondensates," Bulletin of the Chemists and Technologists of Macedonia, Vol. 17, No. 2, 1998, pp. 77-88.

[25] H. M. M. Ayoub, H. E. Nasr and H. H. M. Darweesh, "Characterization and Utilization of Polystyrene and Polyarylamide-Graft Methoxypoly-Ethylene as Cement Admixture," Polymer-Plastics Technology and Engineering, Vol. 45, No. 10-12, 2006, pp. 1307-1315. 